\title{
Marketing of renewable energy sources
}

\author{
Yaroslav Lavrinenko ${ }^{1, *}$, Victoria Tinyakova ${ }^{2}$, Larisa Shishkina ${ }^{3}$ and Ruben Partevian ${ }^{4}$ \\ ${ }^{1}$ Voronezh State Technical University, Moskovsky Prospekt, 14, Voronezh, 394026, Russia \\ ${ }^{2}$ State University of Management, Ryazansky Prospekt, 99, Moscow, 109542, Russia \\ ${ }^{3}$ Voronezh State Agrarian University named after Emperor Peter I, Michurina Street, 1, Voronezh, \\ 394087, Russia \\ ${ }^{4}$ Moscow University of Finance and law MFUA, Serpukhovskiy Val, 17, Moscow, 115191, Russia
}

\begin{abstract}
The article discusses the importance of marketing in the market of renewable energy sources. Alternative energy and its development significantly depend on the country and the climatic conditions of a particular area. In Russia, alternative energy, its development, lags behind world leaders. There are several reasons for this. The first reason is the large reserves of fuel and energy raw materials and their low cost. The second reason is the low utilization rate of the installed capacity of alternative energy. The third reason is that the weather conditions in Russia are nonhomogeneous and not very suitable for the development of alternative energy. A promising direction for the development of alternative energy is small alternative energy. Marketing is built on effective market segmentation, increasing end-user awareness and customer education efforts. The article also provides recommendations for improving the effectiveness of marketing, its special features, taking into account altruism, paternalism and moral satisfaction of customers.
\end{abstract}

\section{Introduction}

Marketing of renewable or alternative energy sources is based on the capabilities of alternative energy itself and the conditions of specific countries and regions. To understand the possibilities of marketing of renewable energy sources in Russia, it is necessary to consider the reasons for its underdevelopment, problems that impede development, as well as promising opportunities for alternative energy.

There are several main reasons for the lag in the development of "alternative" energy in Russia. To begin with, we will determine that in our work alternative energy refers to sources that use primarily the energy of the sun and wind. The Russian Federation has many resources, cheap classical sources of electricity, such as gas, oil and coal. This is the main reason for the lag in the development of alternative energy.

Countries that are actively developing alternative energy, countries where it is successfully operating, have different initial infrastructure data. This concerns compact geographical networks, vast government expenses on renewable energy sources and compensations like dedicated fields for wind systems. In addition, the possibility of returning energy to city networks becomes an important point $[1,2]$.

\footnotetext{
* Corresponding author: yaroslav_lav1@bk.ru
} 
It is worth separating the concepts of renewable and alternative energy. Renewable energy is the energy of hydroelectric power plants. In the Russian Federation, about 20 percent of the total capacity and about 17 percent of the generated energy comes from hydroelectric power plants. We hold the second place in terms of hydropower potential. Alternative energy most often refers to solar panels and windmills [3].

The development of alternative or renewable energy also depends on the effectiveness of marketing. The generation of alternative energy by households is not on the list of priority purchases or necessary services. Therefore, classical marketing must be transformed for effective application.

\section{Materials and Methods}

The development of alternative energy based on the use of wind and solar energy is associated with difficulties. Let us consider the rational reasons for the insufficiently active development of alternative energy in Russia in Fig. 1.
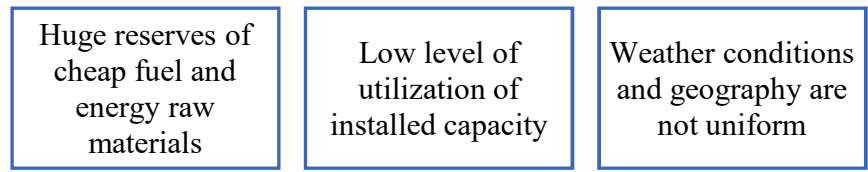

Fig. 1. Rational reasons for insufficient development of alternative energy.

Reason 1. Russia, indeed, has huge reserves of fuel and energy raw materials. The Russian Federation ranks seventh in oil reserves and first in gas reserves. In addition, Russia also ranks third in coal reserves. Given that raw materials are sold cheaply in the domestic market, the reasons for the low development of alternative energy are obvious. It should be noted that the generated energy of classical sources is more expensive than the "conditionally free" solar and wind energy, however, the infrastructure for classical energy sources has already been created in Russia.

Creating infrastructure for alternative energy costs much more than the classic options for generating energy. If you take into account the expensive Russian loan, where even a mortgage is issued at $9 \%$ per annum, then the cost of initial capital investments increases even more. Often, experts say that $1 \mathrm{~kW}$ of power received from the sun and wind can cost about $\$ 1,000$. This is comparable to the cost of gas stations of similar capacity.

The difference between alternative sources and classical ones is that it is not always possible to obtain the declared power from the constructed alternative energy source. If gas or coal have installed power utilization factors at the level of 0.4-0.6, then alternative ones often get 2-5 times less. This is due to weather conditions, when the wind is not always blowing at $10 \mathrm{~m} / \mathrm{s}$ and the sun is not constantly at midday.

As a result, we receive comparable nominal capital investments in the alternative energy option, but efficiency is much lower in the conditions of real efficiency and capital investments. In practice, investment efficiency is 3 times lower than declared. The authors take into account that the cost of generating $\mathrm{kW}$ of alternative energy is also 3 times less, since the wind is free of charge, and the gas is not. However, coal and gas stations can also generate heat, which is very important for the most territories of vast Russia.

Certainly, each specific case of the use of alternative energy requires separate calculations. In regions where not so much thermal energy is required, where there are affordable credit conditions and relatively warm winters, the economic effect of introducing alternative energy may be more noticeable. 
Reason 2. To the considered above reason for the low coefficient of the utilization of installed capacity of alternative energy, a lack of guarantees for obtaining stable energy from alternative sources is added.

What should one do in cases of changing weather conditions, increased cloud cover and lack of wind? If we use only alternative energy, this will lead to the direct dependence on weather conditions. In case of cloudiness, somewhere a machine might stop working, subway trains would stop going. Therefore, for such cases, classic sources of electricity are needed.

The presence of classical energy sources implies the availability of infrastructure, as well as their constant readiness to join the generation of energy. A similar system will be of low efficiency. There are questions of the transfer of electricity costs. In theory, these costs should be transferred to alternative energy, but, most often, they are transferred to the classical options for energy generation.

Alternative energy, being free of charge, brings additional costs that must be considered. Consequently, the percentage of alternative energy can be at a certain level, but not higher than critical. The permissible level of presence of alternative energy sources is 10-15 percent, however, increasing it to 25 percent will create additional infrastructure costs.

Reason 3. The weather conditions in Russia are rather nonhomogeneous, the geography of consumers and favorable weather conditions vary. Let us first consider the wind potential. It is high along the shores of the Arctic Ocean and in the Far East. Assessing the potential of the Far East, wind generation really has prospects, since there is the possibility of obtaining energy and its consumption. In the case of the coast of the Arctic Ocean, there are no consumers. In addition, the operating conditions are complex: low temperatures and high humidity. If it is compared with the wind generation of European countries or China, the difference is significant. The conditions for wind generation in Russia are presented in Fig. 2.

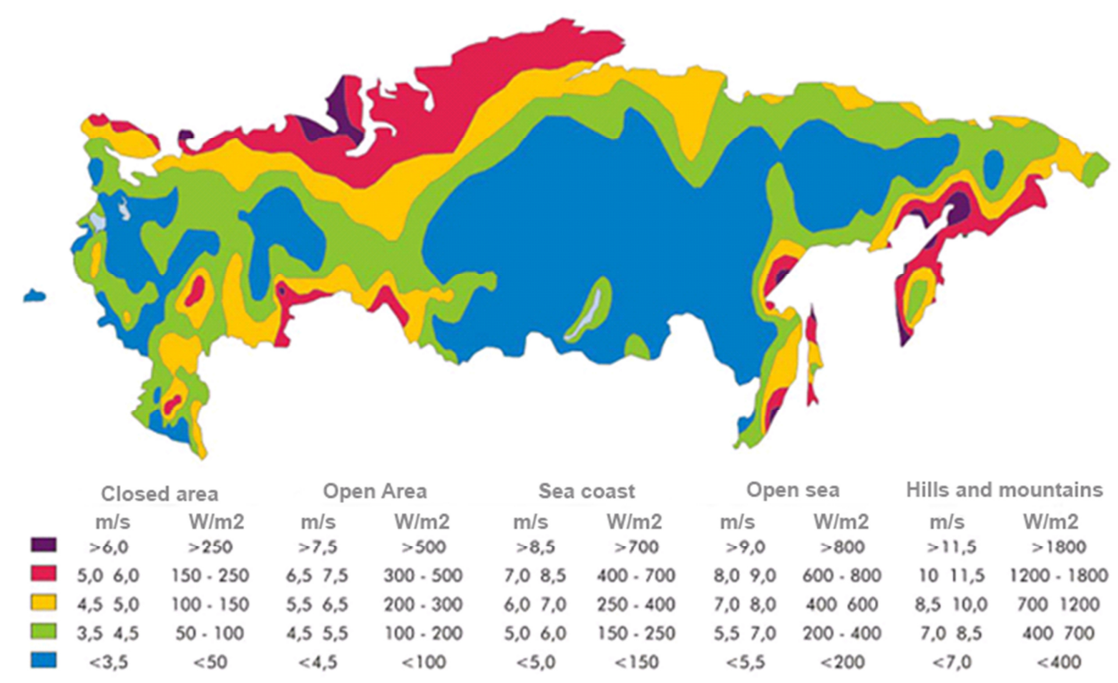

Fig. 2. Conditions for wind generation.

Solar energy can also be efficiently generated within a limited territory of Russia. The installed capacity utilization factor above 0.1 is difficult to obtain in almost all of the Russian Federation. However, Yakutia, the southern regions of Russia and the Far East are suitable for generating solar energy. But to get CUF 0.25 at the level of the Chilean desert is not possible. The distribution of Kcal per square centimeter is shown in Fig. 3. 


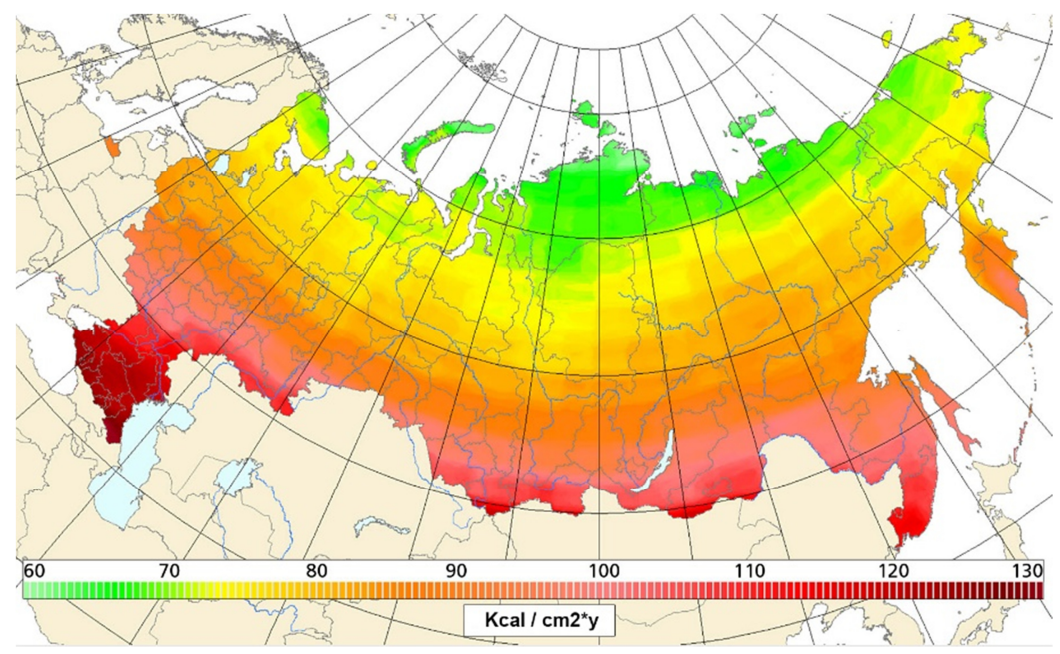

Fig. 3. Distribution of solar energy on the territory of the Russian Federation.

Carrying out the research, the authors noted that, in addition to the reasons why alternative energy does not develop, there are a number of possible prospects for the development of energy. First of all, it is worth starting from the existing Russian reality in the field of energy. One should not blindly copy the experience of leaders in the field of alternative energy.

The choice for Russia turns out to be small alternative energy. Energy, which is tied to a specific circle of consumers. The effectiveness of small energy becomes apparent when evaluating the cost of electricity:

- up to $1 \mathrm{rub}$. / kWh cost on the generating side;

- up to $4 \mathrm{rub}$. / $\mathrm{kWh}$ on the consumer side.

The conclusion is obvious: the introduction of alternative energy sources on the consumer side gives a 4 times higher effect than on the side of a large energy generator. First of all, we are talking about solar energy and wind energy. Energy consumers in private homes are motivated to lower electricity costs and are financially secure to solve these problems regardless of financial benefits and government support. Cost-effectiveness for small alternative energy refers to a period of 10 years.

Small alternative energy will be able to encourage the physical consumer to rational usage and saving of resources . Solar energy will be able to help classical generating energy with daily peaks in consumption. However, energy production by solar panels is unlikely to exceed $5 \%$ in the next 10 years.

Another prospect of electricity generation by alternative energy is coordination with energy supplying organizations of the possibility of receiving electricity from end consumers. This requires the installation of bidirectional meters. At night, electricity is consumed from a classic supplier. After the appearance of the sun, energy consumption decreases and the generation of solar electricity increases. After reaching the parity between the consumption of electricity by the final consumer and the generation of solar energy, the flow of electricity from the classical supplier is stopped. Further, excess electricity is discharged into the city network, the electric meter begins to rewind, to its previous values.

Let us consider as an example the electricity tariff, where $1 \mathrm{kWh}$ costs 30 conventional units. Of these, the cost of electricity itself is about 7 conventional units, and the rest is taxes, duties, profit of sales companies, etc. Electricity is billed at the end of the billing period equal to one calendar month. Three options are possible: 
- the generated electricity by the end consumers is less than the total consumption and payment for the consumed electricity occurs at the base rate;

- the generated electricity by the end consumer is equal to the consumption of the house, in this case, it is not required to pay for electricity;

- the generated electricity by the final consumer is higher than the consumed and the distribution company will pay for it at a tariff that includes only electricity itself at a price of 7 conventional units.

The approach described above stimulates the end consumer to generate as much electricity as he consumes and the balance tends to zero. Generating more electricity is not profitable, as it will not pay back the investment. As a result, we get a mechanism that reduces energy consumption by individuals, but without the difficulties of adapting the finished network to receiving capacity.

Unfortunately, the Russian network does not allow the unloading of excess electricity into the network by individuals. If the surplus is to be accumulated, it is necessary to use storage batteries that nullify all the savings. To implement the mechanism, the Russian electricity networks lack only the legal and regulatory framework.

Based on the presented problems of the development of alternative energy, we highlight the promising areas for the development of marketing of renewable or alternative energy:

1. Massive small alternative energy is possible with the permission for individuals to unload the "surplus" of electricity, at the condition of the deduction of previously shipped energy.

2. Reasonable government support for alternative energy in the most promising areas, primarily the Far East.

3. Alternative energy for power supply of autonomous hard-to-reach facilities.

Based on the indicated directions of marketing development, the main direction of marketing alternative or renewable energy sources is the marketing of small alternative energy. In our work, we will consider it.

Marketing of small alternative energy can be defined as the promotion of receiving energy, which is produced in the framework of environmentally friendly and sustainable means, including wind, solar and hydropower. In the study, we consider individuals or private households.

In order to effectively apply small alternative energy marketing, it is necessary to evaluate the market, private households or end customers. End-user values can be divided into two large groups:

1. Demographic indicators: income level, gender, age, education level and current place of residence.

2. Psychographic indicators: the level of altruism, susceptibility to consumer efficiency and the perception of environmental problems.

After identifying consumer groups with similar demographic and psychographic indicators, it is possible to form a strategy for each group. For example, perceiving consumer efficiency, which is expressed in the fact that end consumers can influence the environmental situation [4-6]. Consumers who want to counteract environmental degradation will want to get tangible benefits from actions that are associated with small alternative energy.

Therefore, marketing of small alternative energy should be aimed at ensuring that the company and its products are perceived through products and services, as well as through the work of the company and its customers. The income of a potential customer may not be as important as the feeling of involvement in the conservation of the environment and caring attitude towards it.

If measured by the life cycle of consumers, then consumers of alternative energy sources are innovators and early adopters. It is these users who are calmly dealing with 
complex products that are not perfect enough, giving manufacturers and companies feedback. For such users, it is important that the company is recognizable, that it provides consistent quality and broadly supported product and service infrastructure. Such consumers are difficult to satisfy, but they are most important for the success of the company.

In the marketing of small alternative energy, an important distinction is made between knowledge and awareness. Knowing the potential contribution of an environmentally friendly product is an important characteristic, which is reflected in the customer's desire to pay. Many potential clients assume that they will be able to support environmental movements and alternative energy [7, 8]. However, their intentions are not consistent with their behavior. However, those potential consumers who have specific knowledge are more likely to respond to marketing tools. Accordingly, an important component of a marketing strategy should be the provision of knowledge.

Education of potential consumers is the key task of the marketer in the context of alternative energy. Consumers must understand the technical details of the products, their applications. Education is obliged to clarify possible incorrect perceptions of alternative energy. The success of a marketing strategy depends directly on how integrated the marketing efforts are, concerning the education and the creation of consumer value $[9,10]$. Marketing is required to inform consumers about the level of efficiency and long-term economic benefits that a consumer can receive.

Customers must be aware that specific actions are causing environmental changes. Consumer efficiency, which is perceived by customers, combined with consumer altruism increase confidence in renewable energy. Therefore, companies in the field of alternative energy should not be associated with classical energy.

Renewable electricity generated is more expensive than classical electricity. Therefore, consumers, choosing alternative sources of electricity, are ready to pay a premium for:

- sensations of the so-called effect of warm glow in comparison with the majority of society;

- the feeling of moral satisfaction;

- implementation of the need for altruism and paternalism;

- emotional satisfaction.

The main problems in implementing the marketing strategy for small alternative energy are presented in Fig. 4.

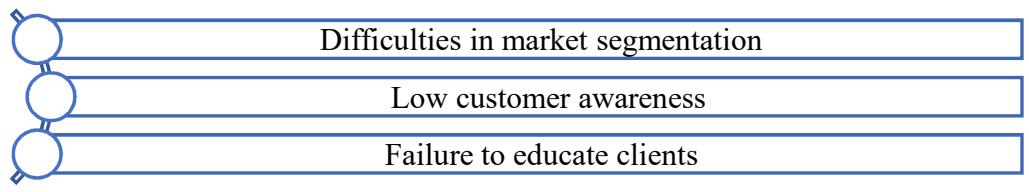

Fig. 4. Main problems in implementing the marketing strategy for small alternative energy.

Difficulties in market segmentation. The mass market approach for small alternative energy is not acceptable. The implementation of electricity sources without studying the indicators of consumers, which are presented above, is quite complicated. Free sources that are available on the Internet are truly accessible to consumers. However, different types of potential and current customers have a different degree of commitment or personal liabilities for the environment. Effective marketers apply the division into different segments, forming a certain way of thinking among consumers, based on differing levels of commitment. Here it is necessary to highlight the benefits that will be effective for one or another group of end customers.

Low awareness. Currently, only one out of five households has ever thought or knew about the possibilities of alternative electricity. It is necessary to raise the awareness in 
order to generate electricity in this way. Alternative energy is not a high priority product. A marketing strategy that focuses on consumers searching for the necessary information sources for the decision making becomes less effective when only one in five households has thought about alternative energy. Therefore, this approach limits the availability of knowledge and is highly dependent on consumers themselves who have already begun to seek knowledge. This is a problem for creating a favorable attitude towards renewable energy sources.

Inability to educate customers. Electricity that satisfies only functional or instrumental needs will not be of interest to customers. Knowledge is important for creating certain attitudes and implementing the necessary consumer behavior. Lack of the necessary knowledge to make decisions becomes a cause for uncertainty, which raises the concerns and risks that are transferred over to the purchase.

A low level of involvement in products like electricity can be influenced by using inertial theories of consumer choice. The problem of choice can be solved not only by functional goals, but also by non-functional goals, which were mentioned above: the development of paternalism, altruism and an increase in the degree of moral satisfaction. Here, the buyer feels a sense of participation and realization, taking care of the environment. Already involved potential buyers are in search of information and analyze its large volume. Therefore, marketers must clearly differentiate alternative energy.

\section{Results}

Effective marketing of renewable energy sources should take into account marketing trends. Regardless of the chosen direction, marketing is obliged to work with customers where they are present. Currently, if marketing does not work with social networks, then in fact it does not exist. The latest trend is the use of stories on social networks. Alternative energy marketing is required to use stories. Companies and end consumers have long been using social networks such as Facebook and Instagram. They talk about their history, work, events, achievements and failures. Sharing your stories with other users of social networks is a fairly effective and completely nonintrusive way of marketing renewable energy.

Voice search is becoming increasingly popular among mobile device users. SEO of the voice search needs to be optimized. Optimization also lies in the speed of loading the site and its reactions on mobile devices and all platforms. Next is the optimization of text information. It should be simple and straightforward. Companies post information in a sufficiently professional language in accordance with the company's policies and brand, but often overdo it in an effort to show their professionalism. The text must be written, relying on simple voice search queries. The use of semantic keywords will be quite effective, but in a limited amount.

Most search engines and social networks provide the ability to place advertising messages for mobile devices only. Users search for information on their mobile phones when they need products and devices. For example, solar batteries. Geographic targeting provides the ability to show ads to users who are looking for solutions in a particular area or region.

The following points are presented as recommendations for the implementation of marketing for renewable energy sources, which are shown in Fig. 4. 


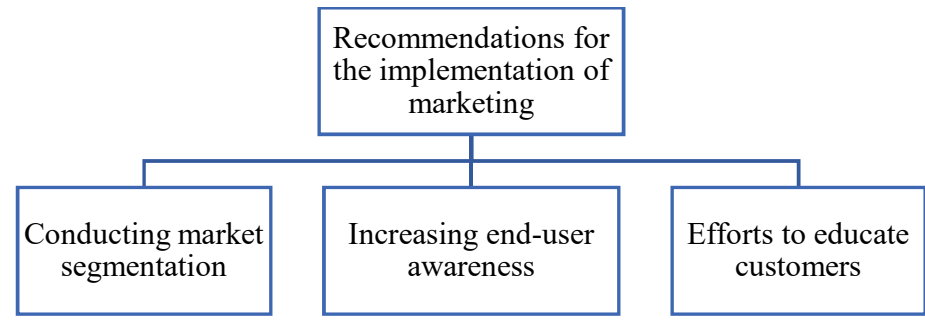

Fig. 5. Main problems in implementing the marketing strategy for small alternative energy.

Market segmentation.

Poor quality or lack of market segmentation is a potential for the development of a company's marketing in the field of alternative energy. An in-depth understanding of the characteristics of end customers leads to the fact that marketing takes on forms that meet the needs of specific users, overcomes a number of objections, especially in terms of the cost of initial capital investments. Despite the fact that the alternative energy market offers great opportunities, covers a wide range of needs, there are ways to improve the marketing. Segmentation should be carried out not only according to demographic and psychographic indicators, but also concern such matters as a tendency to altruism, paternalism and the desire for moral satisfaction. In addition, users of alternative energy, most often, are innovators and early adopters, which, of course, must be considered when segmenting.

Increasing end-user awareness.

If consumers are not aware of alternative energy and its impact on the environment, then they will not buy and install such systems. The priority is to increase the recognition of the company, its products and services. A sufficiently effective advertising policy is to strengthen the advertising campaign during periods of worsening weather conditions. Linking climate change, environmental degradation with alternative energy, as an opportunity to make a difference. Consumers need to understand how they can contribute to the green world.

Customer education efforts.

The success of small alternative energy marketing is associated with efforts to integrate education into a marketing strategy. Education is becoming the key to alternative energy consumers. The provision of benefits, both functional and non-functional, increases the effectiveness of marketing. Knowledge of consumers about how they affect the environment gives possibilities to increase sales. In addition, price premiums payout occur due to increasing perceived consumer efficiency.

\section{Conclusions}

Renewable energy marketing must take the characteristics of end customers into account, functional and non-functional characteristics that contribute to the choice in favor of alternative energy.

Considering the attitude of end customers to an innovative product provides two key advantages. The first advantage is that the positive and negative aspects in the characteristics of innovative products can be determined and effectively managed. The second advantage, the marketing strategy needs to be controlled in order to attract the most receptive audience.

In our work, the reasons for the lag of Russian alternative energy and the ways of its development were highlighted. Some indicators that complicate the adoption of renewable energy sources are given. Marketing of small-scale alternative energy mistakenly ignores the deepening of consumer knowledge and education. We are sure that it is small 
alternative energy that has great potential for development in Russia, considering adequate marketing of renewable energy.

\section{References}

1. J. Rudniak, MATEC Web Conferences 174, 01010 (2018) DOI: https://doi.org/10.1051/matecconf/201817401010

2. S.A. Isaev, N.I. Vatin, S.V. Guvernyuk, V.G. Gagarin, B.I. Basok, Y.V. Zhukova, High Temperature 53(6), 873-876 (2015) DOI:10.1134/S0018151X15040136

3. S. Mydock III, S.J. Pervan, A.F. Almubarak et. al., Marketing Intelligence \& Planning 36.1, 32-48 (2018) DOI: https://doi.org/10.1108/MIP-06-2017-0116

4. L. Eagle, A.O. McCarthy et al., Australasian Marketing Journal (AMJ) 25.2, 141-148 (2017) DOI: https://doi.org/10.1016/j.ausmj.2017.04.006

5. P. Hartmann, V.A. D'Souza et al., Rediscovering the Essentiality of Marketing (Springer, Cham, 2016)

6. C. Herbes, C. Friege, Marketing Renewable Energy: Concepts, Business Models and Cases (Springer International Publishing, 2017)

7. V. Tinyakova, Y. Lavrinenko, A. Blinov, Economic and Social Development. Book of Proceedings (2018)

8. Y. Lavrinenko, V. Tinyakova, A. Kalashnikov, A. Novikov, E3S Web of Conferences. EDP Sciences 110, 02138 (2019) DOI: https://doi.org/10.1051/e3sconf/201911002138

9. D. Sangroya, K.N. Jogendra, Journal of cleaner production 151, 393-405 (2017) DOI: https://doi.org/10.1016/j.jclepro.2017.03.010

10. C. Friege, H. Carsten, Marketing Renewable Energy (Springer, Cham, 2017) 